\title{
Molecular insights into the enhanced performance of royal jelly secretion by a stock of honeybee (Apis mellifera ligustica ) selected for increasing royal jelly production
}

\author{
Solomon Zewdu Altaye, Lifeng Meng, Jianke Li \\ Institute of Apicultural Research/Key Laboratory of Pollinating Insect Biology, Ministry of Agriculture, Chinese \\ Academy of Agricultural Sciences, Beijing 100081, China
}

Received 4 January 2019 - Revised 28 March 2019 - Accepted 30 April 2019

\begin{abstract}
The genetic selection of a high royal jelly (RJ)-producing strain of bees (RJBs) from Italian bees (ITBs) has been conducted for nearly four decades in China since the 1980s. RJBs are the most important producers of RJ in the world and produce $>90 \%$ of the total output with an annual market value of $>\$ 40$ million. With technological advancements in proteomics, the mechanism underpinning the high RJ production by RJBs has been explored to new depths in the last decades. Here, we give an overview that the mechanism driving the enhanced performance of RJ secretion by RJBs. First, the selection of RJBs, high-efficiency technology for RJ production, and advances in genetic characterization of RJBs are reviewed. Then, proteome and phosphoproteome characterization that decipher the augmented RJ production using honeybee organs and tissues are summarized. This may be potentially useful in gaining a complete mechanistic insight into the high performance of RJ yields in honeybees, and expands understanding of the honeybee biology.
\end{abstract}

Italian bees / royal jelly bees / royal jelly production / molecular basis - proteome

\section{INTRODUCTION}

Whole-genome sequencing revolutionized a wide cascade of biological research and brought an opportunity for a more thorough investigation of areas like insect development, physiology, and evolution (Suryamohan and Halfon 2015). It is with the completion of genome sequencing of A. mellifera, together with technological advances in protein separation and mass spectrometry (MS) resolution, sensitivity, and accuracy, that proteomics has become one of the most important tools in addressing the wide aspects of honeybee biology such as physiology, behavior, and pathology (Valcu and Kempenaers 2015; Hao and Li 2016).

Corresponding author: J. Li, apislijk@126.com Handling editor: Klaus Hartfelder
Honeybees are commonly known for their production of valuable substances such as honey, RJ, propolis, and other products (Bogdanov et al. 2008). $\mathrm{RJ}$ is a special food for young larvae and the honeybee queen throughout her lifetime. Because of this, it is assumed that RJ extends the lifespan of queen bees relative to worker bees (Fratini et al. 2016). $\mathrm{RJ}$ is rich in nutrients such as proteins, sugars, vitamins, and a large number of bioactive substances, such as a 10-hydroxy-2-decenoic acid (10HDA) (Viuda-Martos et al. 2008). The 10-HDA is a special component of a lipid fraction in RJ (Blum et al. 1959; Lercker et al. 1981), which has antibiotic and immunomodulatory activities (Townsend et al. 1959; Vucevic et al. 2007). Some of the RJ proteins such as major royal jelly proteins (MRJPs) (Mairesse et al. 1998), jelleines (Fontana et al. 2004), and royalisin (Fujiwara et al. 1990) are reported to have properties of antimicrobial, antifungal, anti-tumor, anti-diabetic, and anti-hypertensive 
activities (Bíliková et al. 2001; Oka et al. 2001; Tokunaga et al. 2004). In addition, RJ regulates inflammation, oxidative stress, and vasodilation activity (Okamoto et al. 2003; Liu et al. 2008; Nakajima et al. 2009; Kolayli et al. 2016; Yang et al. 2018). These RJ-induced activities are widely believed to help maintain homeostasis and recover from pathological conditions; therefore, $\mathrm{RJ}$ has been used as a cosmetic, health food, or dietary supplement (Ramadan and Al-Ghamdi 2012; Cornara et al. 2017; Yoneshiro et al. 2018). RJ affects the immune system, including malignant tumors, under a variety of physiological and pathological conditions, not only stimulating immune-active cells but also stimulating antibody production (Melliou and Chinou 2005; Izuta et al. 2009; Yuksel and Akyol 2016; Kocot et al. 2018). Based on some facts, there is a hypothesis that RJ may have some health benefits (Miyata and Sakai 2018), but without a conclusive evidence (e.g., clinical trials), no causal relationship can be established between the consumption of RJ and the claimed health benefits (EFSA Panel on Dietetic Products N.a.A.N 2011). Further information could be found from recent reviews on the composition of $\mathrm{RJ}$ and its potential utilization (Ramadan and Al-Ghamdi 2012), the origin and function of the honeybee MRJPs (Buttstedt et al. 2014), and its antimicrobial properties (Fratini et al. 2016) and medicinal value (Bogdanov 2017), and its potential applications for cancer treatment (Miyata and Sakai 2018).

To increase RJ outputs, huge efforts have been made for bee scientists and beekeepers in China. The genetic selection of a high RJ-producing strain of bees (RJBs, $A$. $m$. ligustica) from Italian bees (ITBs) has been conducted for nearly four decades in China since the 1980s. The RJBs can now produce 10 times greater amount of RJ than ITBs (Li et al. 2007a, b; Li et al. 2010; Feng et al. 2015; Han et al. 2015). Given the significantly elevated RJ outputs by RJBs, China is now the world's largest RJ producer and produces $\sim 3500$ tons of RJ per year, which accounts for more than $90 \%$ of the world RJ market (Krell 1996; Cao et al. 2016; Fratini et al. 2016). Many factors are likely to influence RJ production by honeybees (Cao et al. 2016). It was in the year 2003 that the performance of RJBs for enhanced RJ yield was identified as an inheritable trait
(Li et al. 2003a, b). Since then, attempts have been made to elucidate the molecular basis of these augmented yields. The questions that have been given emphasis include the following: how do the RJBs achieve the high performance of RJ production? Is there any difference in protein components between the RJ of RJBs and the lower productions of other honeybee species and/or lines?

In order to attempt to answer these questions, various types of studies have been performed in recent decades (Cao et al. 2016). Some of the identified markers of RJBs are morphological. For instance, the correlation between length of the hypopharyngeal glands (HGs) and RJ production is positive, and length of the HGs has been recommended as one of the markers associated with RJ outputs ( $\mathrm{Su}$ and Chen 2003). In addition, seven microsatellite DNA loci (159 bp at A29,100 bp and $104 \mathrm{bp}$ at A24, $110 \mathrm{bp}$ at A7, $126 \mathrm{bp}$ at A43, $221 \mathrm{bp}$ at A14, and $221 \mathrm{bp}$ at A113) are found as possible molecular markers of the RJBs (Chen et al. 2005). Although these markers are important for marker-based selection, knowledge on the molecular mechanism that drives the stronger performance of $\mathrm{RJ}$ production by RJBs is still required. To be noted, recent proteome researches have revealed that RJBs have reshaped the proteome setting of the HGs (Li et al. 2010; Ji et al. 2014), mandibular glands (MGs) (Huo et al. 2016), hemolymph (Ararso et al. 2018), and nervous system (Han et al. 2015; Han et al. 2017), to support their biological performance for the elevated RJ production, as compared to ITBs and other honeybee species and/or lines. In addition, proteome, phosphoproteome, and glycoproteome comparisons of RJ from RJBs and/or other honeybee species/lines have been carried out (Li et al. 2007a, b; Chen and Li 2009; Fang et al. 2010). For instance, proteomic analysis of the RJB HGs reveals a group of upregulated proteins involved in energy metabolism and protein biosynthesis etc. (Li et al. 2010), which matches with the fact that the HGs of the RJBs could secrete more RJ than those of ITBs. With regard to the protein complements in $\mathrm{RJ}$ produced by high and low RJ producing bee stocks/lines, there is a significant difference found between Carnica bees and RJBs or ITBs, whereas 
there is no significant difference found between RJBs and ITBs (Li et al. 2007a, b). Moreover, there are significantly abundant protein species found in the RJ of RJBs relative to in that of Apis cerana cerana (Acc) (Fang et al. 2010). Here, we focus on the scientific community's attention to the cluster of current knowledge on the mechanistic understanding of enhanced RJ production. First, we give an overview of the selection process of RJBs, high-efficiency RJ production technology, advances in genetic characterization of RJBs, biological significance of RJ from different honeybee species or lines, and genetic and molecular basis of enhanced RJ secretion. Furthermore, the proteome and phosphoproteome of honeybee organs and tissues that underlie molecular differences for strengthened RJ production are also reviewed. This provides useful information on the mechanistic insight into the high performance of RJ yields by RJBs and it expands our understanding of the honeybee biology.

\section{OVERVIEW OF THE SELECTION PROCESS OF RJBS}

From as early as the 1930s, ITBs (Apis mellifera ligustica) from Japan were introduced in China by a Chinese ambassador. Since then, the ITBs have experienced tremendous expansion in colony number in China. In 1994, the number of Italian bees and other Apis mellifera sub-species reached over 6 million colonies, and now over 9 million colonies, accounting for $1 / 10$ th of the world total number (http://www.fao. org/faostat/en/\#home).

$\mathrm{RJ}$ is one of the most important products for Chinese beekeepers. Regarding the technology of RJ production, China started producing RJ following the method reported by French literature in 1957 (Chen 1989). The history of the high RJ bee lineage is summarized by Cao et al. (2016). Initially, before the start of the high $\mathrm{RJ}$ production breeding program, China's RJ production was only $0.2-0.3 \mathrm{~kg} /$ colony/year (Chen 2005). In the $1950 \mathrm{~s}$, due to the increased demand for RJ, the beekeepers in Zhejiang Province invented the RJ production method using $A$. m. ligustica queenright colonies (CNCAGR 2011). The main concept of RJ collection from the colony is the application of handmade wax-based queen cells, which are fixed on wooden bars and put the wax queen cells with grafted larvae into the queenless chamber of the hive. Although this technological setup works well, the RJ yields are quite low. Normally, a colony can produce about $20 \mathrm{~g}$ in a 72-h cycle. During this process, beekeepers have recognized the importance of productive honeybee stocks and developed new tools. Since the 1960s, beekeepers in parts of Zhejiang Province have tended to select $A$. m. ligustica colonies for improved RJ production (CNCAGR 2011). After more than 20 years of semi-controlled breeding, the RJ yield of each colony in some apiary farms increased to $2.0-3.0 \mathrm{~kg} /$ year (Chen 2005). In 1979 , the production of RJ started on a mass scale, and the output was about 150 tons that year (Qiu 1999). Since 1980, the Chinese government has noticed the importance of the product to the country and has begun investing in the selection program. In 1986, a stock of honeybees was reported to be selected from ITBs by beekeepers in Zhejiang Province, a stock that could produce an average of $87.43 \%$ higher amount of RJ than non-selected lines at that time (Wencheng et al. 1989). The selection process improved the production ranging from 6.0 to $8.0 \mathrm{~kg} /$ colony/year in the 2000s (Chen 2005). Through continuous selection, RJBs can now produce more than 10 times (normally $10 \mathrm{~kg} /$ colony/year) the amount of RJ of native ITBs ( $\mathrm{Li}$ et al. 2003a, b; Huo et al. 2016; Ararso et al. 2018). Currently, China produces $\sim 3500$ tons of RJ each year, covering over $90 \%$ of the international RJ market of which Japan, the USA, and Europe are the major importers (Zheng et al. 2011).

\section{H I G H - E F F I C I E N C Y R J PRODUCTION TECHNOLOGY}

Over the past 40 years, the increase in the production of RJ in China has mainly been made possible due to developmental refinement of RJBs (Li 2000; Li et al. 2003a, b; Chen 2005; Li et al. 2007a, b; Feng et al. 2015; Hu et al. 2017), and the development and implementation of production techniques that allow the increase and optimization of RJ production (Li 2000; Li et al. 2003a, b; $\mathrm{Li}$ and Aiping 2005; Cao et al. 2016; Hu et al. 
2017). A standard procedure for RJ production (Fig. 1a-f) in China has been summarized by Li and his colleagues $(2003 \mathrm{a}, \mathrm{b})$. In brief, the requirements for high RJ production are found to include the following: good queen, large and strong colony throughout the bee season (the more populous the colony, the better for RJ production), sufficient food supply (including honey and pollen), agreeable temperature $\left(20-30^{\circ} \mathrm{C}\right)$, efficient tools for RJ production, and experienced beekeepers. Of these, the good queen is the most important factor that influences the overall performance of RJ yields of a colony.

The development and implementation of powerful tools play an important role in the efficient production of RJ. The use of modern RJ production facilities such as plastic queen cells, larval grafting tools, and plastic spatulas made it possible to produce RJ on a large scale ( $\mathrm{Li} 2000$; $\mathrm{Li}$ et al. 2003a, b; Li and Aiping 2005). For instance,

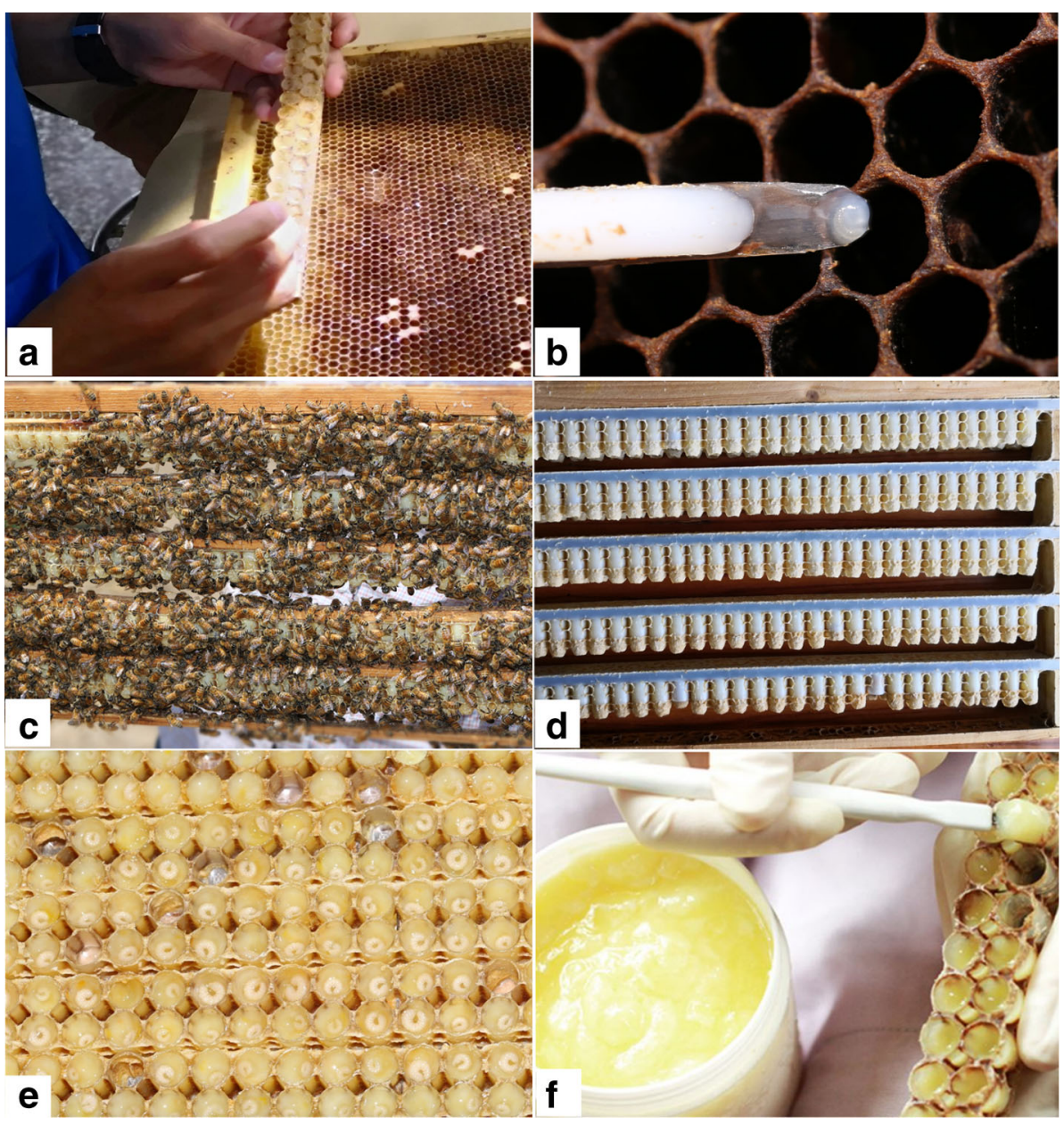

Figure 1. A standard procedure for RJ production. A standard procedure for RJ production in China $(\mathbf{a}, \mathbf{b}, \mathbf{c}, \mathbf{d}, \mathbf{e}$, and, f) involves the following steps: 1-day-old larvae are grafted into plastic queen cups mounted on bars; the bars are put into the queenless portion of the colony, separated by a queen excluder (NBs then feed the larvae in the queen cups with royal jelly); the bars are removed from the colony after about 3 days; larvae are removed from the queen cups using forceps; and the RJ is collected with a plastic spatula and packed. In addition to this, the necessary tools for royal jelly production like plastic queen cells, transfer tools, forceps and plastic bottle, and experienced beekeepers are required. Moreover, a typical royal jelly producing colony should be two stories and must also be populous. Photographs are provided by Professor. Dr. Jianke Li. 
the introduction of the plastic queen cell cups fixed on a wooden strip in the 1980s became an innovative step (Chen and Lin 1987; Liu et al. 2011). The replacement of the handmade waxbased queen cells with the plastic queen cells was a revolutionary step. The use of these plastic queen cells could improve the RJ production by 20-30\% (Liu et al. 2011; Zheng et al. 2011). Moreover, recently, a bionic non-grafting larva ovipositor was designed, which excluded the larval grafting stage and significantly reduced the labor intensity required for RJ production (Zhang et al. 2013; Wu et al. 2015). Moreover, the development of RJ collecting machines has enabled large-scale RJ production by reducing labor and improving harvesting efficiency (Liu et al. 2011). For instance, the machine (Fig. 2a, b) could harvest at least $12 \mathrm{~kg}$ of $\mathrm{RJ}$ in 40 min once the larvae are taken out from the plastic queen cells. The integrated techniques and tools have improved the average RJ yield of RJBs per colony to about $200 \mathrm{~g}$ in a 72 -h production cycle and $10 \mathrm{~kg}$ per year (Zheng et al. 2011). In general, owing to decades of research on the development of high RJ-producing strains, implementation of modern RJ production techniques and facilities, coupled with extensive experience of Chinese beekeepers in raising and managing colonies for efficient RJ production have greatly contributed to the increased RJ yields (Cao et al. 2016; Hu et al. 2017).

\section{GENETIC CHARACTERIZATION OF RJBS}

Since the successful selection of RJBs, the genetic characterization of this line has been conducted. The RJ producing ability of honeybees is a quantitative trait and is dominated by genotypic effects (Li et al. 2003a, b). Genetics of the RJB lineage is first described using allozymes as molecular markers (Yin et al. 2011). A microsatellite-based study shows a genetic differentiation between RJBs and ITBs, and a high degree of polymorphism within RJBs (Chen et al. 2005). In another study, genotype and allele frequencies, and degree of homozygosity reveals significant variation between workers of RJBs and ITBs (Liang-xian et al. 2004), which is due to the effects of genes

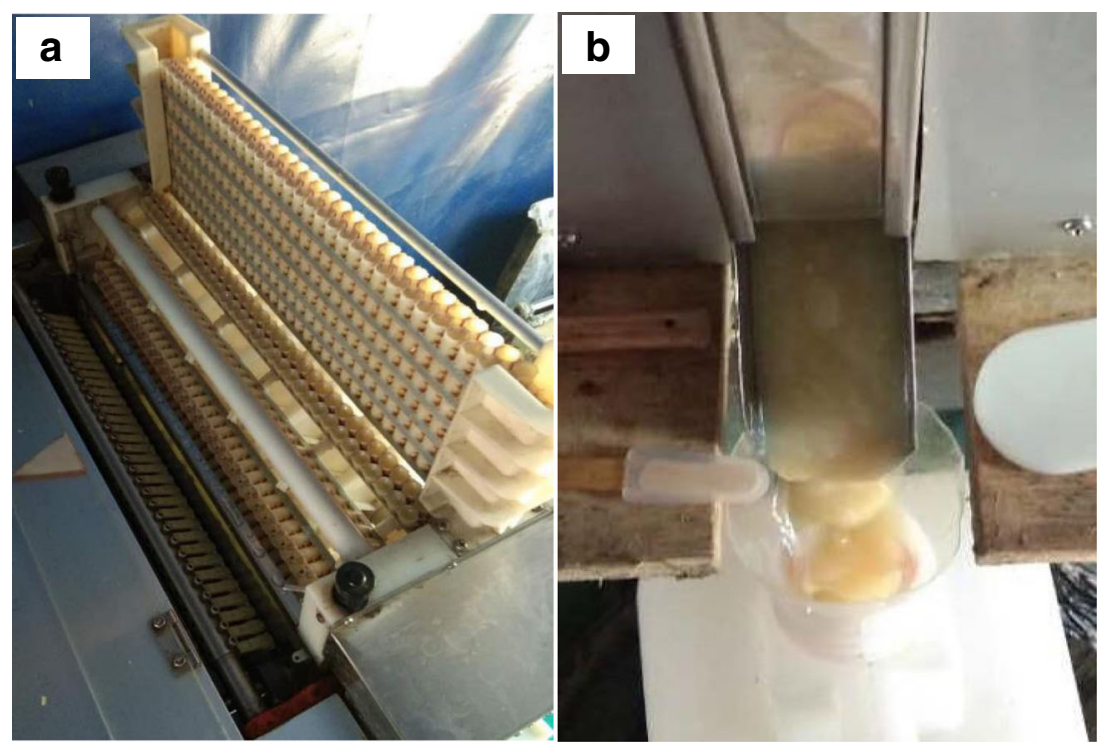

Figure 2. The development of automatic RJ collecting machines has enabled large-scale RJ production, both by reducing labor and improving harvesting efficiency. a shows the part of the machine where the plastic queen cells containing the RJ is inserted and extracted, $\mathbf{b}$ shows the outlet for the extracted RJ on the machine. Once the larva is taken out from the plastic queen cells and becomes ready for extraction, the machine could harvest at least $12 \mathrm{~kg}$ of $\mathrm{RJ}$ in $40 \mathrm{~min}$. 
that respond to artificial selection as a result of their favorable effect on a selected trait in the RJB lineage (Cao et al. 2016). Furthermore, the RJBs are found to contain a 632-bp of DNA fragment at a higher frequency than ITBs (Liang-xian et al. 2004), and compared to ITBs, the trait for high $\mathrm{RJ}$ production is found to associate with a 316-bp DNA fragment in RJBs (Zhang et al. 2001). Moreover, the frequency of certain alleles (A7, A14, A24, A29, A43, and A113) is found to correlate with RJ production, and these alleles are suggested as markers for high RJ production (Chen et al. 2005).

A cDNA microarray was used to asses gene expression levels and identify differentially expressed genes between the RJBs and ITBs (Nie et al. 2017). Specifically, three genes: MRJP4, $60 \mathrm{kDa}$ heat shock protein, and heat shock $70 \mathrm{kDa}$ protein cognate 3 , and other genes, such as ribosomal protein, skeleton, and proteasome, are up-regulated in the head of RJBs relative to ITBs (Nie et al. 2017). This is consistent with the proteome data of the $\mathrm{HG}$ development of worker bees of RJBs and ITBs (Li et al. 2010). The up-regulated MRJP 4 in RJBs both at the transcriptional and proteomic levels suggest that the abundance of MRJPs may be increased, as MRJP 4 is a major protein for total RJ (Schmitzová et al. 1998; Albert et al. 1999). The ribosomal proteins, heat shock proteins, and proteasome in the head of RJBs (Nie et al. 2017) are consistent with other studies on the HGs (Feng et al. 2009; Li et al. 2010; Ji et al. 2014), suggesting that they may involve in nursing behavior by accelerating protein biosynthesis. In addition, a comparative genetic analysis of three stocks of Western honeybees: the RJBs, ITBs, and Chinese ITBs, reveal that RJ output and queen cell acceptance (Fig. 3) are genetically dominant traits (Li et al. 2003a, b). All above-mentioned information is suggestive of the facts that genetic selection for increasing RJ yields on RJBs may differentiate the genetic structures as compared with ITBs, thereby the molecular basis involved in high $\mathrm{RJ}$ production between both bee stocks may be further divergent.

\section{MOLECULAR INSIGHTS INTO THE R J B S A C H I E V I N G H I G H PERFORMANCE OF RJ YIELDS}

Proteomics is becoming an important tool for describing bee biology at the molecular level (Zewdu Ararso et al. 2018). The molecular basis of different organs and tissues that allow bees to perform their biological tasks has been explained on the proteome scale, for example in the brain (Hernandez et al. 2012; Chan et al. 2013; Han et al. 2015; Han et al. 2017; Meng et al. 2018), hemolymph (Ararso et al. 2018), embryo (Fang et al. 2014; Fang et al. 2015), antennae in Varroa resistance (Parker et al. 2012; Hu et al. 2016), and venom (Matysiak et al. 2014; Matysiak et al. 2016; Matysiak et al. 2017).

In the past few years, extensive research has been conducted to gain insight into the molecular basis for enhanced RJ production in RJB. To achieve a $10 \times$ higher RJ yield, RJB workers adjusted different proteomics strategies by enhancing

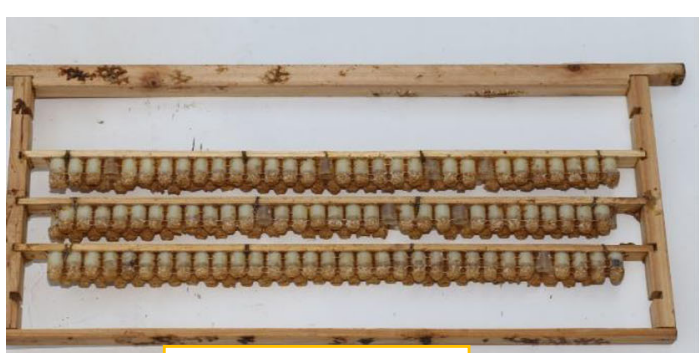

a RJBs

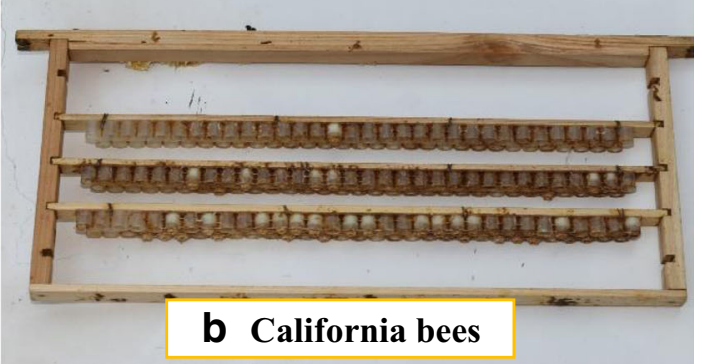

b California bees

Figure 3. RJ output and queen cell acceptance are genetically dominated traits. Genome sequencing of RJBs and California bees have found significant genetic variation, and queen cell acceptance in RJBs (a) is higher than in California Bees (b ). Photographs are provided by Professor. Dr. Jianke Li. 
wider ranges of pathways as compared to the ITB workers ( $\mathrm{Li}$ et al. 2010). For example, in $\mathrm{HG}$ of $\mathrm{RJB}$, up-regulated proteins are involved in pathways such as protein biosynthesis, protein folding, and carbohydrate metabolism, suggesting that their biological effects are induced to enhance glandular activity, thereby enhancing RJ secretion ( $\mathrm{Li}$ et al. 2010). In addition, phosphorylation has been shown to regulate the protein activity of $\mathrm{HG}$ at all ages of worker bees, suggesting that phosphorylation optimizes the biochemical activity of worker bees HG (Qi et al. 2015). In RJB NB, the pathways of protein synthesis and energy metabolism are functionally induced to consolidate enhanced RJ secretion compared to ITB (Hu et al. 2019). Also, in RJBs enhanced levels of neuropeptides are involved in regulating water homeostasis, brooder pheromone recognition, foraging ability, and pollen collection to regulate RJ secretion behavior (Han et al. 2015). Moreover, in nurses of RJB, the activity of phosphatidylinositol signaling and arachidonic acid metabolism is increased to enhance the olfactory response to larval pheromone stimulation (Han et al. 2017). The mandibular gland of RJB also selectively improved lipid synthesis-related pathways to maintain an appropriate ratio of 10hydroxy-2-decenoic acid, an important fatty acid in $\mathrm{RJ}$, for larval nutrition, also contributes to the increase RJ production (Huo et al. 2016).

The following subsections provide detail discussions of the molecular basis of different organs and tissues, enabling RJB to function in higher RJ production. At last, we also summarize the literature on the species-specific biological effects of RJ by comparing the proteome, phosphoproteome, and glycoproteome of $\mathrm{RJ}$ from RJBs and other honeybee species.

\subsection{Proteome comparison of HGs of honeybee workers between RJBs and ITBs}

The worker bees' ontogeny depends on the differential expression of proteins in organs and tissues in concert with their distinct age-dependent physiology. RJ is secreted by young workers, and $\mathrm{RJ}$ protein is a cocktail secretion of three glands: hypopharyngeal, postcerebral, and thoracic glands (Fujita et al. 2013), and most of the RJ proteins are secreted by HGs of the nurse bees (NBs) (Fujita et al. 2013; Ji et al. 2014). The HGs are located in the anterior part of the bee's head (Li et al. 2008) and each gland consists of hundreds of oval acini that are attached to an axial duct that opens into the sub-oral part of the hypopharynx (Ohashi et al. 1997; Deseyn and Billen 2005).

The HGs are the most important organ to secrete RJ. Morphologically, the size of the acini in HGs radically changes with age development (Albert et al. 2014, Ji et al. 2014), reaches their peak at about day 6 , and decreases after day 15 during the active seasons (Feng et al. 2009). The activity of the HG is positively correlated with its size (Deseyn and Billen 2005). Specifically, the amount of RJ secretion is positively correlated with the acini size (Albert et al. 2014). Physiologically, the HGs and their acini size are well studied (Crailsheim and Stolberg 1989). The HGs develop mainly during the nursing stage of individual bees and degenerates in forager bees (FBs), although at an early stage of foraging, bees still have welldeveloped HGs (Sasagawa et al. 1989). With the age-dependent roles of worker bees, the proteins synthesized by the HGs vary (Kubo et al. 1996). In NBs, the HGs develop a high rate of protein synthesis, but the gland activity reverts in FBs (Ohashi et al. 2000). Moreover, depending on the role of the worker bee in the colony, the biological function of the HGs changes from secreting RJ in NBs to producing digestive enzymes (sucrose hydrolyzing enzymes) in FBs (Simpson et al. 1968; Kubo et al. 1996; Ohashi et al. 1997; Moraes and Bowen 2000). Biochemically, the gland expresses specific genes in the NBs and FBs to fit with their age-related roles. In the HGs, major proteins synthesized change from RJ in NBs to $\alpha$-glucosidase in of FBs (Ohashi et al. 1996). In FBs, the produced proteins in HGs such as $\alpha$-glucosidase, glucose oxidase, galactosidase, esterase, lipase, and leucine arilamidase are used in the process of converting nectar into honey (Kubo et al. 1996; Ohashi et al. 1999; Deseyn and Billen 2005; Santos et al. 2005). Furthermore, in the HGs, abundance level of MRJPs changes with age and with task ( $\mathrm{Li}$ et al. 2010), and peak levels of proteins in the HGs occur during day 6-12 in NBs (Feng et al. 2009). Notably, the age at which the HGs of the RJBs and ITBs 
potentially start RJ secretion varied. The HGs of RJB may have the potential of RJ secretion on day 3 after emergence, whereas this is day 6 for ITBs (Feng et al. 2009).

Proteomics has been widely applied to reveal the molecular basis of enhanced RJ production in RJBs. To attain a tenfold greater RJ yield, the RJB workers have adapted a different proteomic strategy by enhancing wider ranges of pathways as compared to the ITB workers (Fig. 4) (Li et al. 2010). For instance, in the HGs of RJBs, the upregulated proteins are implicated in pathways such as in protein biosynthesis, protein folding, and carbohydrate metabolism, suggesting their biological roles are induced to boost the gland activity that in turn enhances $\mathrm{RJ}$ production ( $\mathrm{Li}$ et al. 2010). Moreover, across ages of worker bees, phosphorylation is shown to regulate protein activity of HGs, showing that phosphorylation optimizes the biochemical activity of the HGs of worker bees (Qi et al. 2015). For instance, phosphorylation regulates proteins involved in key biological pathways, such as the centrosome cycle, mitotic spindle elongation, macromolecular complex disassembly, and ribosome. Here, in the RJBs, the trait of high RJ production is shown to associate with several important proteins and pathways. However, the specific activity of these proteins in related pathways still remains to be further investigated.

\subsection{Proteome comparison of MGs during the adult life between ITBs and RJBs}

The biological function of the MGs secretion has both a reproductive and a non-reproductive role in the colony (Plettner et al. 1996). Secretions from the MGs have important caste-specific functions that are associated with the social evolution of honeybees (Vallet et al. 1991; Wu et al. 2017). In worker bees, the MGs secrete lipids for larval nutrition and pheromones. Using proteomics, the regulatory mechanism that determines the development of MG and the metabolism involved in lipid and pheromone synthesis in both RJBs and ITBs is well investigated (Huo et al. 2016).

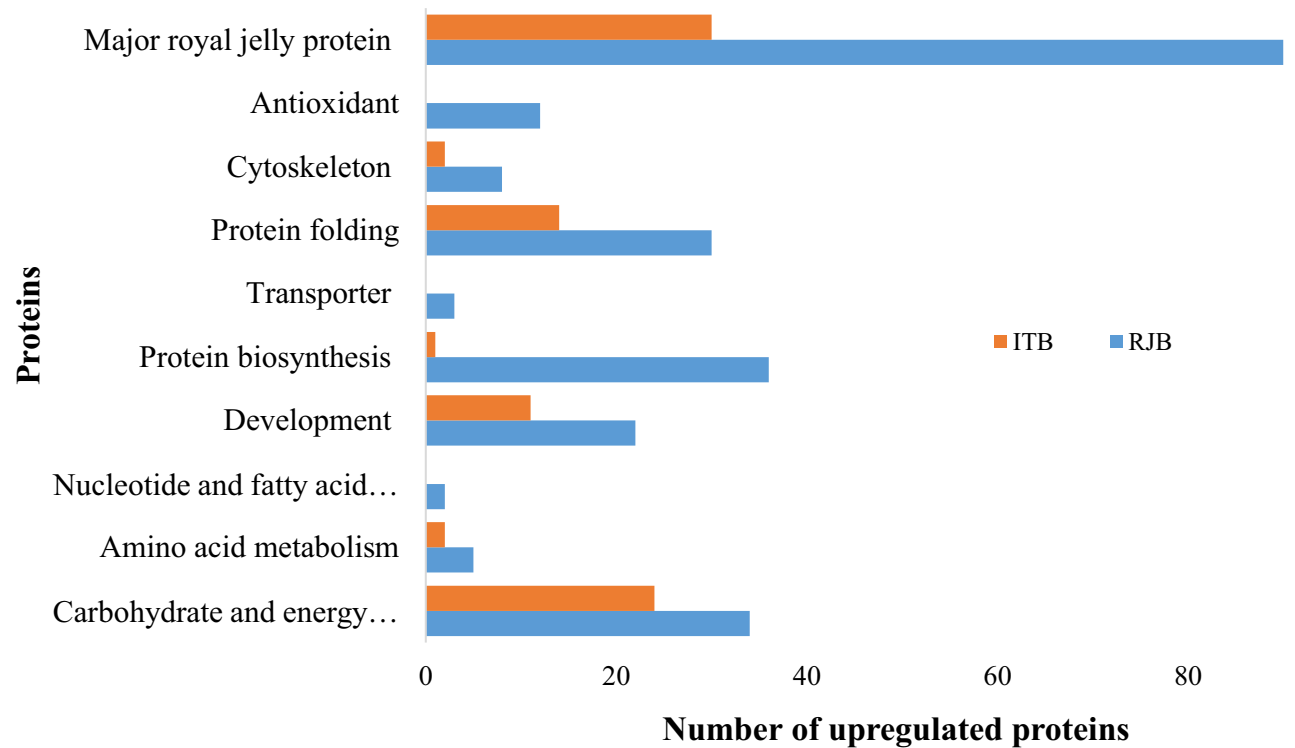

100

Figure 4. Proteome of HGs of RJB workers consolidates wide ranges of proteins as compared to ITB. In HGs of RJBs, the up-regulated proteins like protein synthesis and energy metabolism are implicated in a wide range of pathways to boost the HGs' functionality, such as protein biosynthesis, protein folding, and carbohydrate metabolism. Blue and red bars represent the number in the RJB and the ITB, respectively. Data were used from Li et al. (2010). 
The proteome analysis of MGs of worker RJBs and ITBs across ages (NEBs, NBs, and FBs) shows a wide range of different biological process that defines different programs to underline the specific role of the sub-casts in the colony (Huo et al. 2016). For instance, in NEBs, the proteome shapes the initiation of young MG development; in NBs, it drives high secretory activity in lipid synthesis, whereas in FBs, it synthesizes scent markers to increase foraging efficiency by inducing activities such as lipid metabolism and small molecules. Notably, in NBs, specific and highly abundant proteins are mainly enriched in pathways related to substance transport and lipid synthesis, indicating their priority in priming high secretory activity in lipid synthesis as larval nutrition. It is through this process that the NBs of RJBs contribute to the elevated RJ production by maintaining the required proportion of lipids (a major component of RJ) through activated lipid synthesis and minimizing its degradation to increase 10-HDA synthesis (Huo et al. 2016).

\subsection{Neurobiological basis of elevated RJ production: brain membrane proteome and phosphoproteome comparison of RJBs and other honeybee species and/or lines}

Among the different roles of NBs, one is to feed the queen and the larvae aged less than 3 days with RJ. RJ is largely blended from the secretion of the HGs and MGs, these two glands reshaped their proteome to drive the gland development and functionality for augmented RJ production (see previous sections). The brain of RJB nurses has developed a unique neuropeptidome in response to enhanced RJ production, as RJ secretion is behavior performed by NBs. For instance, in RJBs, the enhanced level neuropeptide implicated in regulating water homeostasis, brood pheromone recognition, foraging capacity, and pollen collection, suggests their involvement in the regulation of RJ secretion (Han et al. 2015). Moreover, both membrane proteome and phosphoproteome have evolved unique settings to adapt to the elevated RJ secretion. Likewise, across all adult phases, more membrane proteins are expressed in the brain of RJBs than of ITBs
(Fig. 5a, b). In each stage of both ITBs and RJBs, the identified membrane proteins are enriched in a similar pathway coverage (Fig. 5c) (Han et al. 2017). For instance, across the adult stages, significantly enriched and shared pathways include oxidative phosphorylation, protein processing in the endoplasmic reticulum, phagosome, endocytosis, and wnt signaling pathway. However, protein export and dorso-ventral axis formation pathways are only enriched in NEBs and on day 7, lysosome pathway is only found in NBs and FBs, and phototransduction is exclusively enriched in FBs.

The molecular basis of the enhanced performance of RJ secretion by RJBs is well explained by the up-regulated proteins and phosphoproteins in the brain (Han et al. 2015; Han et al. 2017). The up-regulated protein and phosphoprotein enhance the RJ production by facilitating larval pheromone and flower odor recognition. For instance, in the brain of RJB nurses and foragers, the up-regulated proteins are involved in pathways such as the wnt signaling pathway, endocytosis, and soluble Nethylmaleimide-sensitive factor attachment protein receptor interactions in vesicular transport, which involve in facilitating larvae pheromone and flower odor recognition via the release and absorption of signal molecules that increase nerve sensitivity. Moreover, compared to ITBs, in RJBs the up-regulated phosphoproteins related to efficient neurotransmitter transmission and recycling may have played a role in increasing RJ yields via enhancing larval feeding of NBs and increasing the nutrient supply of the colony through facilitating efficient food collection or foraging.

Furthermore, the RJBs shaped their brain membrane proteome and phosphoproteome settings to match the nursing and foraging behaviors in response to enhanced RJ production (Han et al. 2015). For instance, in RJB nurses (Fig. 6a), the up-regulated proteins implicated in water and ion homeostasis and brood pheromone recognition (diuretic hormones and periviscerokinin, and tachykinins (TK), respectively), shows higher physiological activity involved in the RJ secretion process compared to ITBs (Han et al. 2015). Whereas in RJB forager (Fig. 6b), the highly abundant proteins are supposed to enhance 

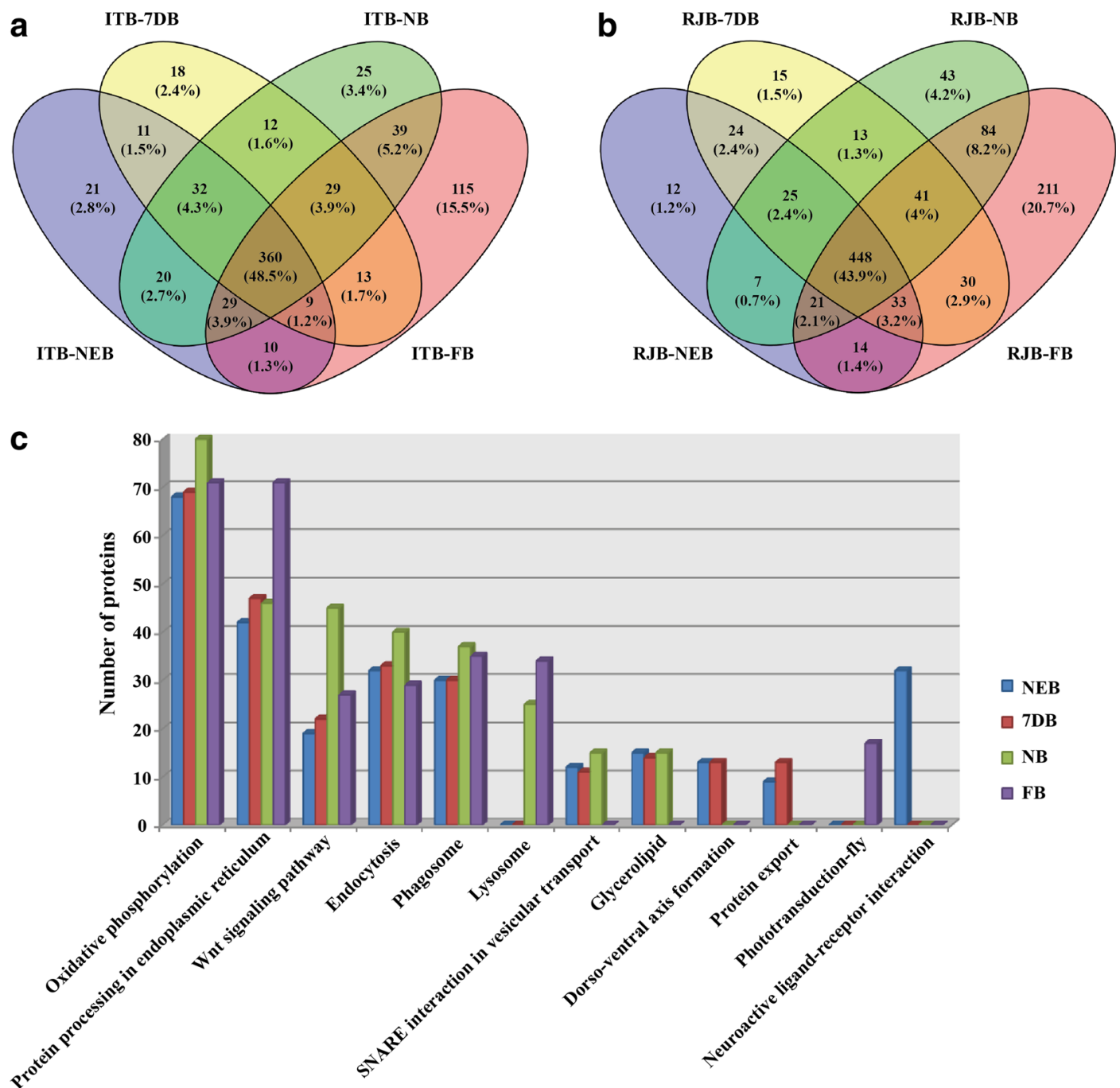

Figure 5. The brain membrane proteome comparison across the four stages during age-related polyethism in honeybee workers (Apis mellifera ligustica). Venn diagrams show the distribution of identified membrane proteins in $\mathbf{a}$ the Italian bee (ITB) and $\mathbf{b}$ the royal jelly bee (RJB) at four stages of adult worker bees: newly emerged bee (NEB), 7-day-old bee (7DB), nurse bee (NB), and forager bee (FB). c Significantly enriched KEGG pathways of the identified membrane proteins in each stage. Data were used from Han et al. (2017).

foraging capacity (PDH, sNPF, FMRFamide, Corazonin) and pollen collection (prohormone-4 and TK), which supports the required amount of food and protein supply to enhance the level of RJ production compared to ITBs. In sum, enhanced performance of RJ secretion by RJBs as compared to ITBs is associated with highly enhanced neural peptides that regulate the behavior and elevated RJ secretion via the regulation of water homeostasis, brood pheromone recognition, foraging capacity, and pollen collection (Han et al. 2015). Similarly, in RJB nurses, the enhanced level of phosphatidylinositol signaling and arachidonic acid metabolism contributed for stronger olfaction sense to respond to larval pheromone stimulation, and in RJB foragers, enriched pathways related to signal processing resulted in higher pollen collection efficiency via enhancing 
nerve sensitivity (Han et al. 2017). This forms the basis for the success of decades of selection for enhanced RJ yields. Moreover, immunostaining of the brain and the HGs have shown differential expression of MRJPs in different brain regions of honeybee castes and subcastes (Peixoto et al. 2009), suggesting that the activity level of the brain might be another factor contributing to enhanced RJ production in RJBs.

\subsection{Comparison of hemolymph proteome of RJBs and ITBs}

Hemolymph plays a crucial role in the investigation of various aspects of the honeybee's phenotype and physiology (Chan et al. 2006; Feng et al. 2014; Erban et al. 2016). The honeybee hemolymph comprises a wide range of organic and inorganic substances such as proteins, lipids, carbohydrates, nucleic acid macrophage-like cells, salts, hormones, and degradation products of these compositions (Chan et al. 2006; Bogaerts et al. 2009; Erban et al. 2013). The hemolymph protein components, such as enzymes, nutrient and pheromone transporters, structural proteins, immune response proteins, and MRJPs, vary between developmental stages and physiological conditions and is used to study caste differences as well as development (Chan et al. 2006; Randolt et al. 2008). The hemolymph of the honeybee serves in transportation of biological molecules, nutrients, and hormones, and in immune defense as a strategy to develop and match specific physiology (Feng et al. 2014).

To better understand the mechanism of enhanced RJ production in RJBs, one of the promising strategies is to compare the hemolymph proteome between honeybee species and/or within lines of sub-species. For instance, the comparison between RJB and ITB larval and adult samples shows that both beelines use distinct hemolymph proteome in driving their physiology (Ararso et al. 2018). Particularly, in day 4 larvae of the RJBs, hemolymph proteome consolidates amino acid and protein synthesis to support the development and immune responses, which is the selective pressure that favors high RJ production, and the NBs of RJBs reinforce energy metabolism, protein synthesis, and cellular homeostasis to respond to the increased RJ yields. This implies that the RJBs reprogram their hemolymph proteome to follow a different developmental path and efficient RJ secretion. Moreover, the metabolomic difference in protein synthesis and energy metabolism, for instance, has a dramatic effect on the morphology and physiology of the HGs through participating in proper cell divisions (Ararso et al. 2018).

\subsection{Proteome, phosphoproteome, and glycoproteome comparisons of $R J$ from different honeybee species or lines}

To better understand the biological properties of RJ from RJBs and other honeybee species, comparative investigations on proteome, phosphoproteome, and glycoproteome are conducted. For instance, there is a significant difference in RJ protein complements between Carnica bees and RJBs or ITBs, but there is no significant difference found between RJBs and ITBs (Li et al. 2007a, b). However, controversial results were found on the 10-HDA content of RJ. One study showed a lower 10-HDA content of RJ from high RJB colonies relative to that from ITB colonies (Chen 2005), whereas, in another, a nonsignificant difference in 10-HDA content between the two lines was reported (Huo et al. 2016). The $\mathrm{RJ}$ proteome and function from the two bee species of Apis mellifera ligustica (Aml) and Acc show a profound difference (Fang et al. 2010). Although the protein types are the same, in AmlRJ there is a significantly higher level of MRJPs than in Acc-RJ (Fang et al. 2010). Proteins such as peroxiredoxin 2540, glutathione S-transferase S1, and MRJP5 are identified only in Aml-RJ, and MRJP1 is the most abundant MRJP in $A m l$-RJ. In $A c c-\mathrm{RJ}$, the only protein found is MRJP7, and, similarly to Aml-RJ, MRJP1 is the most highly abundant MRJP. In addition, a significantly higher protein level of MRJP1-5 is found in the Aml-RJ than in Acc-RJ (Fang et al. 2010), whereas the phosphorylated proteins abundance level shows the opposite, with phosphorylated peptides from Acc-RJ showing stronger anti-microbial and antifungal activity (Han et al. 2014). The RJBs and Acc employ unique phosphorylation strategies that 


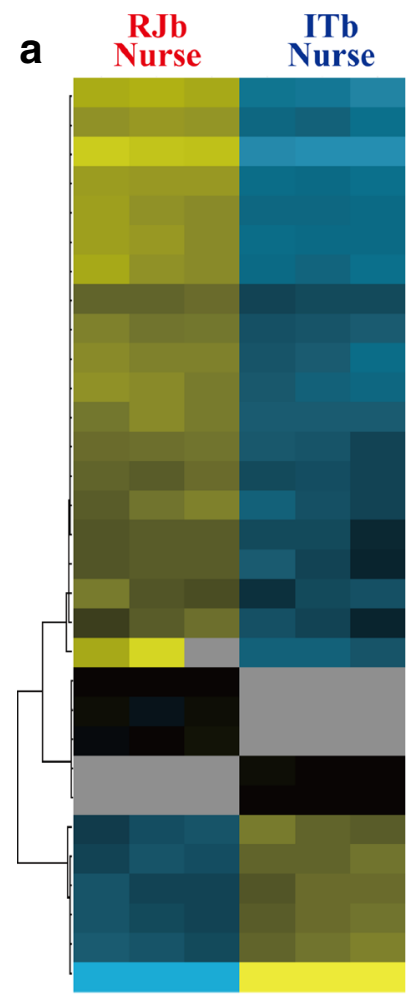

RVPWTPSPRLa
NVGSVAREHGLPYa
LPGSVILRALS
AYRKPPFNGSIFa
RKPPFNGSIFa
pQLHNIVDKPRQNFNDPRF
GLDLGLSRGFSGSQAA
NVASLARTYTLPQNAa
YVASLARTGDLPIRa
GIFLPGSVILRALSRQa
NVGTLARDFALPPa
AFGLLTYPRIa
pQTFTYSHGWTNa
GRNDLNFIRYa
LINSLLGLPKNMNNAa
QITQFTPRLa
TWKSPDIVIRFa
ITGQGNRIF
pQITQFTPRLa
pQITQFTPRL
VPWTPSPRLa
INSLLGLPKNMNNAa
GIFLPGSVILRALS
APMGFQGMRG
ASFDDEYY
ALMGFQGVRa
ASFDDEYYKRAPMGFQGMRa
APMGFYGTRa
ARMGFHGMRa
APMGFQGMRa
APMGFYGTRG
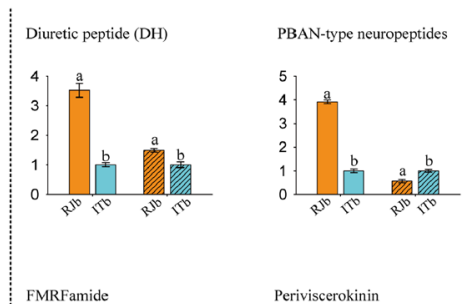

Prohormone-3
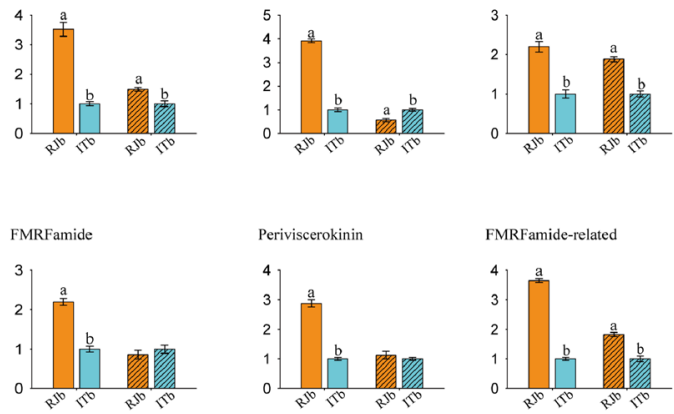

Pigment-dispersing hormone

Tachykinins (TK)
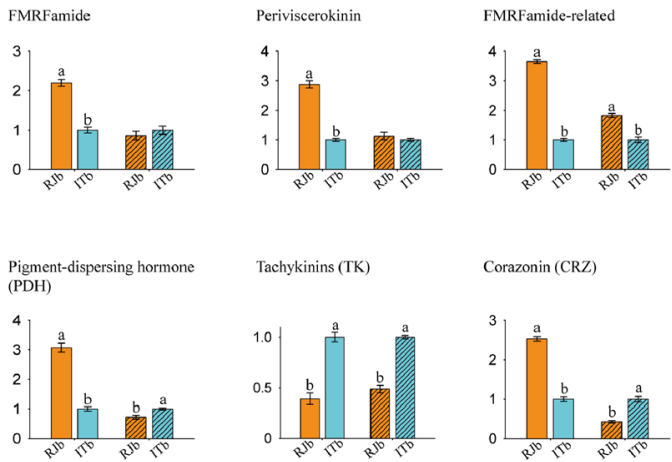

Neuropeptide like precursor 1 (NPLPI)
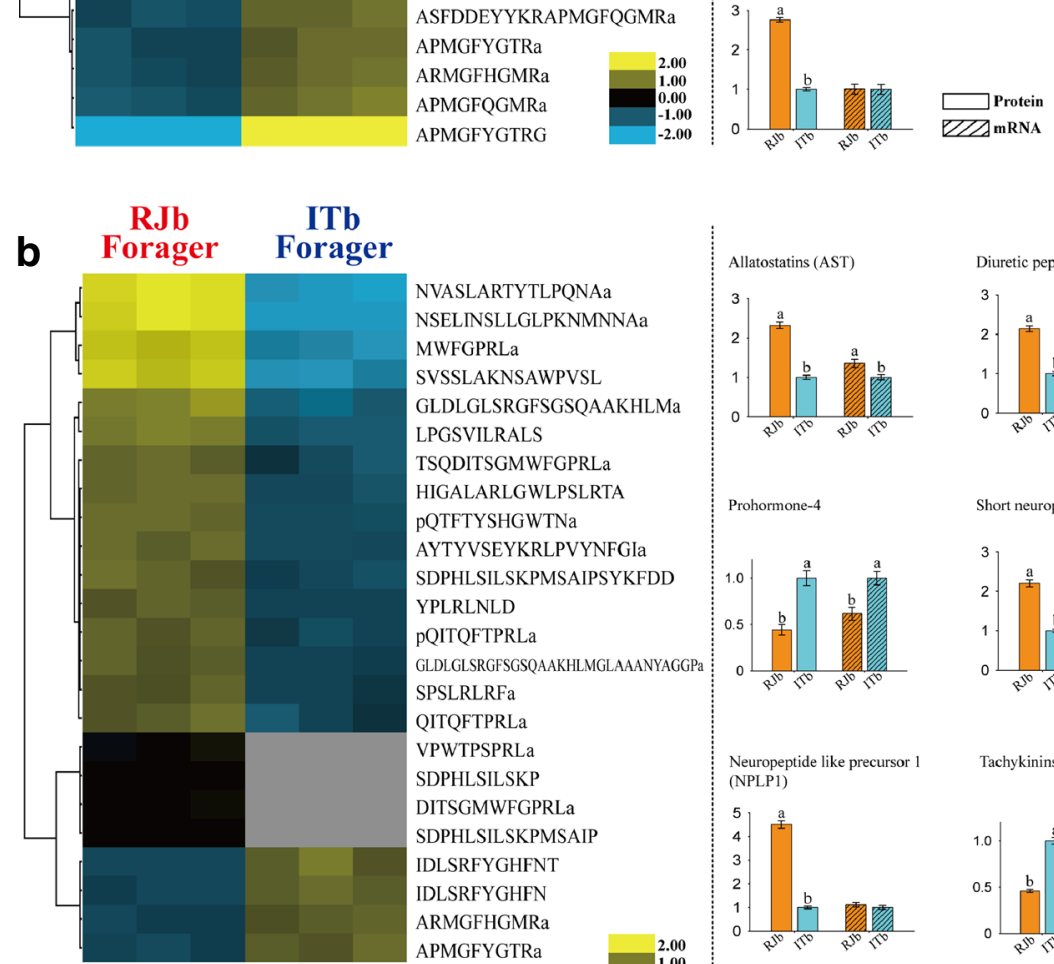

NVASLARTYTLPQNAa NSELINSLLGLPKNMNNAa MWFGPRLa SVSSLAKNSAWPVSL GLDLGLSRGFSGSQAAKHLMa LPGSVILRALS TSQDITSGMWFGPRLa HIGALARLGWLPSLRTA pQTFTYSHGWTNa AYTYVSEYKRLPVYNFGIa SDPHLSILSKPMSAIPSYKFDD YPLRLNLD PQITQFTPRLa GLDLGLSRGFSGSQAAKHLMGLAAANYAGGP SPSLRLRFa QITQFTPRLa VPWTPSPRLa SDPHLSILSKP DITSGMWFGPRLa SDPHLSILSKPMSAIP IDLSRFYGHFNT IDLSRFYGHFN ARMGFHGMRa APMGFYGTRa
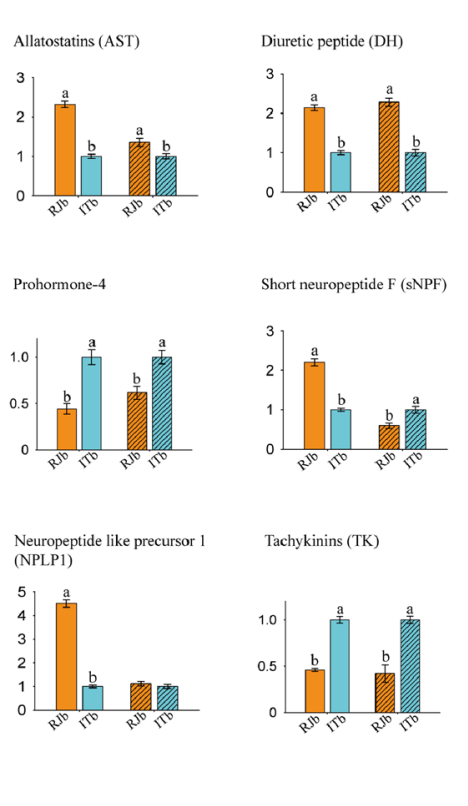

PBAN-type neuropeptides
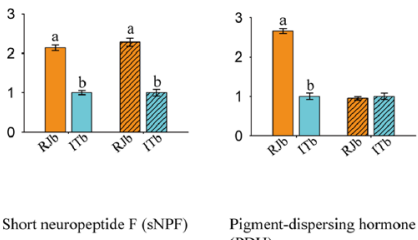

Pigment-dispersing hormon (PDH)
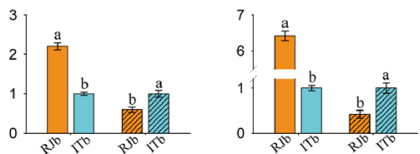

Tachykinins (TK)

Corazonin (CRZ)
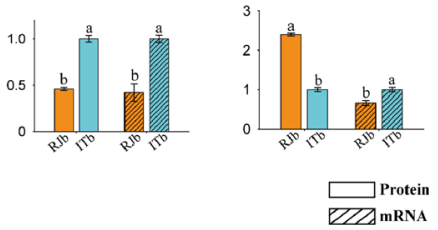
4 Figure 6. Brain membrane of RJBs showed unique proteome and phosphoproteome settings to consolidate nursing and foraging behaviors. a In RJB nurse, the highly abundant proteins, diuretic hormones (DHs), periviscerokinin (PVK), and tachykinins (TK)), are implicated in water and ion homeostasis and brood pheromone recognition, respectively, to underline the elevated physiology of RJ secretion compared with ITBs. b In RJB foragers, the highly abundant proteins: (prohormone-4 and TK) and (PDH, sNPF,

FMRFamide, Corazonin (CRZ)) enhanced pollen collection and foraging capacity, which supports the required amount of food and protein supply to enhance the level of RJ production compared with ITBs. Reprinted with permission from Han et al. (2015).

support their diverse biological characteristics (Han et al. 2014). The abundance level of MRJPs in the two species could be explained better in terms of their biological requirements for survival and development. In Aml MRJPs, abundance is related with supporting their large body size, whereas in $A c c$, high abundance of phosphorylated peptides is to balance the low level of MRJPs by ensuring survival and development (Han et al. 2014).

Phosphoproteome comparison of RJ between the honeybee species also shows a distinct variation. For instance, the RJBs and Acc employ unique phosphorylation strategies that support their diverse biological characteristics (Han et al. 2014). These two bee species have evolved significant variation in phosphosites, peptide abundance, and antimicrobial activity of the phosphorylated RJ proteins. In Am-RJ, 16 phosphoproteins carrying 67 phosphorylation sites are identified, while in Acc-RJ, nine proteins phosphorylated on 71 sites are found. In both RJ samples, eight phosphorylated proteins are common, and the same motif ([S-X-E]) is extracted, indicating that in both honeybee species the function of MRJPs is evolutionarily reserved to act as nutrients and immune agents(Fang et al. 2014). In addition, Zhang and his colleagues (2014) identified 25 $\mathrm{N}$-glycosylated proteins including $53 \mathrm{~N}$ glycosylation sites, of which 42 N-linked glycosylation sites were positioned as novel RJ protein. Of the 42 non-redundant RJ proteins found in $A m l-\mathrm{RJ}, 13$ are novel proteins whose activity is mainly related to metabolic processes and heal improvement (Zhang et al. 2014). In addition to extending the RJ proteome coverage, the newly identified protein provides new information to our knowledge on the biochemical property of RJ, as the identification and characterization of unknown RJ proteins is potentially useful for pharmacokinetic and biological activity (Zhang et al. 2014). Future research should be done to identify possible proteins for such uses.

In RJ, glycosylation modulates many important biological processes that have a vital function for both honeybees and humans. For instance, several $\mathrm{N}$-glycosylated proteins found in RJ are associated with MRJPs, developmental regulation, metabolism processes, and immunity activities (Feng et al. 2015). As a result of species-specific glycosylation of RJ, the two bee species' RJ is endowed with different functional properties (Feng et al. 2015). For instance, in comparison to Acc-RJ, the Aml-RJ lacked antibacterial associated glycosylated apidaecin, hymenoptaecin, and peritrophic matrix, and low inhibitory efficiency of Nglycosylated MRJP2 against Paenibacillus larvae (P. larvae), due to which the Aml larvae were susceptible to P. larvae (Feng et al. 2015). Furthermore, a stronger antihypertensive activity of $\mathrm{N}$-glycosylated MRJP1 in Acc than in Aml was found, which depicts the purpose of specific RJ protein and their modification for the treatment of hypertension for humans (Ramadan and AlGhamdi 2012; Feng et al. 2015). Generally, the two honeybee species have evolved speciesspecific strategies of glycosylation to tune protein activity to acting/serving as nutrients and immune agents, which benefits both the honeybee and adds health-promoting activity for humans. This evidence adds a valuable resource for the investigation of the biological functions of RJ proteins for honeybee and medical communities.

\section{CONCLUSION}

Due to the genetic selection of RJBs from ITBs, both stocks have shaped distinct genetic architecture in RJ production and acceptance of the larvae in queen cells. The differences in behavioral adaptations and biological systems of both bee stocks manifest in their proteome. With the advancement of proteomics technologies, the mechanistic insight into the enhanced RJ secretion 
by RJBs reaches a new depth. However, the genes and proteins that are involved in regulating the stronger performance of RJ yields in RJBs still remain to be discovered. Moreover, despite a large number of new proteins that have been identified at this point, future identification and isolation of individual proteins, such as has been done for MRJP1-5, is required.

\section{ACKNOWLEDGMENTS}

The first author was supported by the Chinese Government Scholarship (CGS)-for Ph.D. Program at CAAS.

\section{FUNDING INFORMATION}

Financial support was provided by the Modern Agro-Industry Technology Research System (CARS-44) and the Agricultural Science and Technology Innovation Program (CAAS-ASTIP2015-IAR) in China.

\section{OPEN ACCESS}

This article is distributed under the terms of the Creative Commons Attribution 4.0 International License (http://creativecommons.org/licenses/by/4.0/), which permits unrestricted use, distribution, and reproduction in any medium, provided you give appropriate credit to the original author(s) and the source, provide a link to the Creative Commons license, and indicate if changes were made.

Aperçu moléculaire dans l'amélioration des performances de la sécrétion de gelée royale par un stock d'abeilles domestiques (Apis mellifera ligustica) sélectionnées pour augmenter la production de gelée royale

Abeilles italiennes / abeilles de gelée royale / production de gelée royale / base moléculaire protéome

Molecular Einblicke in die verbesserte Leistung von Gelée royale-Sekretion durch einen Vorrat an Honigbiene (Apis mellifera ligustica) ausgewählt zur Erhöhung Gelee royale Produktions

Italienische Bienen/Gelée Royale Bienen/Gelée Royale Produktion/molekulare Basis Proteom

\section{REFERENCES}

Albert S., D. Bhattacharya, J. Klaudiny, J. Schmitzová, J. Simúth. (1999) The family of major royal jelly proteins and its evolution. J. Mol. Evol. 49: 290-297.

Albert t., J. Spaethe, K. Grubel, W. Rossler. (2014) Royal jelly-like protein localization reveals differences in hypopharyngeal glands buildup and conserved expression pattern in brains of bumblebees and honeybees. Biology Open 3 : 281-288.

Ararso Z., C. Ma, Y. Qi, M. Feng, B. Han, et al. (2018) Proteome comparisons between hemolymph of two honeybee strains (Apis mellifera ligustica) reveal divergent molecular basis in driving hemolymph function and high royal jelly secretion. J. Proteome Res. 17: 402-419.

Bíliková K., G. Wu, J. Šimúth. (2001) Isolation of a peptide fraction from honeybee royal jelly as a potential antifoulbrood factor. Apidologie 32 : 275-283.

Blum M.S., A.F. Novak, S. Taber. (1959) 10-Hydroxy- $\Delta 2-$ Decenoic acid, an antibiotic found in Royal Jelly. Science 130 : 452-453.

Bogaerts A., G. Baggerman, E. Vierstraete, L. Schoofs, P. Verleyen. (2009) The hemolymph proteome of the honeybee: Gel-based or gel-free? Proteomics 9: 3201-3208.

Bogdanov S. (2017) Royal jelly, bee brood: composition, health, medicine: a review. Bee Product Science: 1-41.

Bogdanov S., T. Jurendic, R. Sieber, P. Gallmann. (2008) Honey for nutrition and health: A review. Journal of the American College of Nutrition 27 : 677-689.

Buttstedt A., R.F.A. Moritz, S. Erler. (2014) Origin and function of the major royal jelly proteins of the honeybee (Apis mellifera) as members of the yellow gene family. Biological Reviews 89: 255-269.

Cao L.-F., H.-Q. Zheng, C.W.W. Pirk, F.-L. Hu, Z.-W. Xu. (2016) High royal jelly-producing honeybees (Apis mellifera ligustica) (Hymenoptera: Apidae) in China. J. Econ. Entomol. 109 : 510-514.

Chan Q.W.T., C.G. Howes, L.J. Foster. (2006) Quantitative comparison of caste differences in honeybee hemolymph. Mol. Cell. Proteomics 5 : 2252-2262.

Chan Q.W.T., M. Chan, M. Logan, Y. Fang, H. Higo, et al. (2013) Honey bee protein atlas at organ-level resolution. Genome Res. 23 (11): 1951-1960.

Chen S.B. (1989) Artificial queen rearing. Agriculture Press, Beijing(In Chinese).

Chen M.H. (2005) Analysis of the current state of royal jelly in China mainland. Journal of Bee 25 : 17-19.

Chen J., J. Li. (2009) Comparative analyses of proteome complement between worker bee larvae of high royal jelly producing bees (A. m. ligustica) and Carniolian bees (A. m. carnica). AGR SCI CHINA 8 : 1219-1227.

Chen S.L., X.Z. Lin. (1987) Study and manufacture of a new type of high production queen cell cup strip in full plastic. Apiculture of China [In Chinese] 2: 9-10. 
Chen S.-L., J.-K. Li, B.-X. Zhong, S.-K. Su. (2005) Microsatellite analysis of royal jelly producing traits of Italian honeybee (Apis mellifera Liguatica). Acta Genetica Sinica 32: 1037-1044.

CNCAGR. (2011) Animal genetic resources in China-Bees. Chinese Agricultural Press Beijing, China.[In Chinese].

Cornara L., M. Biagi, J. Xiao, B. Burlando. (2017) Therapeutic properties of bioactive compounds from different honeybee products. Front Pharmacol 8: 412.

Crailsheim K., E. Stolberg. (1989) Influence of diet, age and colony condition upon intestinal proteolytic activity and size of the hypopharyngeal glands in the honeybee (Apis mellifera L.). J. Insect Physiol. 35.

Deseyn J., J. Billen. (2005) Age-dependent morphology and ultrastructure of the hypopharyngeal gland of Apis mellifera workers (Hymenoptera, Apidae). Apidologie 36 : 49-57.

EFSA Panel on Dietetic Products N.a.A.N. (2011) Scientific Opinion on the substantiation of health claims related to: anthocyanidins and proanthocyanidins (ID 1787, 1788, 1789, 1790, 1791); sodium alginate and ulva (ID 1873); vitamins, minerals, trace elements and standardised ginseng G115 extract (ID 8, 1673, 1674); vitamins, minerals, lysine and/or arginine and/or taurine (ID $6,1676,1677)$; plant-based preparation for use in beverages (ID 4210, 4211); Carica papaya L. (ID 2007); "fish protein" (ID 651); acidic water-based, non-alcoholic flavoured beverages containing calcium in the range of 0.3 to $0.8 \mathrm{~mol}$ per mol of acid with a $\mathrm{pH}$ not lower than 3.7 (ID 1170); royal jelly (ID 1225, 1226, 1227, 1228, 1230, 1231, 1326, $1328,1329,1982,4696,4697)$; foods low in cholesterol (ID 624); and foods low in trans-fatty acids (ID 672, 4333) pursuant to Article 13(1) of Regulation (EC) No 1924/2006. EFSA Journal 9(4): 2083.

Erban T., P.L. Jedelsky, D. Titera. (2013) Two-dimensional proteomic analysis of honeybee, Apis mellifera, winter worker hemolymph. Apidologie 44: 404-418.

Erban T., K. Harant, M. Kamler, M. Markovic, D. Titera. (2016) Detailed proteome mapping of newly emerged honeybee worker hemolymph and comparison with the red-eye pupal stage. Apidologie 47: 805-817.

Fang Y., M. Feng, J. Li. (2010) Royal Jelly Proteome Comparison between $A$. mellifera ligustica and $A$ cerana cerana. J. Proteome Res.: 2207-2215.

Fang Y., M. Feng, B. Han, X. Lu, H. Ramadan, et al. (2014) In-depth proteomics characterization of embryogenesis of the honey bee worker (Apis mellifera ligustica). Mol. Cell. Proteomics 13 : 2306-2320.

Fang Y., M. Feng, B. Han, Y. Qi, H. Hu, et al. (2015) Proteome analysis unravels mechanism underling the embryogenesis of the honeybee drone and its divergence with the worker (apis mellifera lingustica). J. Proteome Res. 14: 4059-4071.

Feng M., Y. Fang, J. Li. (2009) Proteomic analysis of honeybee worker (Apis mellifera) hypopharyngeal gland development. BMC Genomics 10: 1-12.
Feng M., H. Ramadan, B. Han, Y. Fang, J. Li. (2014) Hemolymph proteome changes during worker brood development match the biological divergences between western honey bees (Apis mellifera) and eastern honey bees (Apis cerana). BMC Genomics 15 : 1-13.

Feng M., Y. Fang, B. Han, X. Xu, P. Fan, et al. (2015) Indepth n-glycosylation reveals species-specific modifications and functions of the royal jelly protein from western (Apis mellifera) and eastern honeybees (Apis cerana ). J. Proteome Res. 14 : 5327-5340.

Fontana R., M.A. Mendes, B.M. De Souza, K. Konno, L.M.M. César, et al. (2004) Jelleines: A family of antimicrobial peptides from the Royal Jelly of honeybees (Apis mellifera). Peptides 25 : 919-928.

Fratini F., G. Cilia, S. Mancini, A. Felicioli. (2016) Royal Jelly: An ancient remedy with remarkable antibacterial properties. Microbiol. Res. 192 : 130-141.

Fujita T., H. Kozuka-Hata, H. Ao-Kondo, T. Kunieda, M. Oyama, et al. (2013) Proteomic analysis of the royal jelly and characterization of the functions of its derivation glands in the honeybee. J. Proteome Res. 12: 404411.

Fujiwara S., J. Imai, M. Fujiwara, T. Yaeshima, T. Kawashima, et al. (1990) A potent antibacterial in royal jelly. J. Biol. Chem. 265 : 11333-11337.

Han B., Y. Fang, M. Feng, X. Lu, X. Huo, et al. (2014) Indepth phosphoproteomic analysis of royal jelly derived from western and eastern honeybee species. J. Proteome Res. 13 : 5928-5943.

Han B., Y. Fang, M. Feng, H. Hu, Y. Qi, et al. (2015) Quantitative neuropeptidome analysis reveals neuropeptides are correlated with social behavior regulation of the honeybee workers. J. Proteome Res. 14: 43824393.

Han B., Y. Fang, M. Feng, H. Hu, Y. Hao, et al. (2017) Brain membrane proteome and phosphoproteome reveal molecular basis associating with nursing and foraging behaviors of honeybee workers. J. Proteome Res. DOI: https://doi.org/10.1021/acs.jproteome.7 b00371: 3646-3663.

Hao Y., J. Li. (2016) Proteomic research on honeybee, in: Salekdeh G.H. (Ed.), Agricultural proteomics volume 1: Crops, horticulture, farm animals, food, insect and microorganisms, Springer International Publishing, Cham, pp. 225-252.

Hernandez L.G., B. Lu, G.C.N. da Cruz, L.K. Calabria, N.F. Martins, et al. (2012) Worker honeybee brain proteome. J. Proteome Res. 11 (3): 1485-1493.

Hu H., K. Bienefeld, J. Wegener, F. Zautke, Y. Hao, et al. (2016) Proteome analysis of the hemolymph, mushroom body, and antenna provides novel insight into honeybee resistance against varroa infestation. J. Proteome Res. 15 : 2841-2854.

Hu F.-L., K. Bíliková, H. Casabianca, G. Daniele, F. Salmen Espindola, et al. (2017) Standard methods for Apis mellifera royal jelly research. J. Apic. Res. 8839: $1-68$.

Hu H., G. Bezabih, M. Feng, Q. Wei, X. Zhang, et al. (2019) In-depth proteome of the hypopharyngeal glands of honeybee workers reveals highly activated 
protein and energy metabolism in priming the secretion of royal jelly. Mol. Cell. Proteomics DOI: https://oi. org/10.1074/mcp.RA118.001257.

Huo X., B. Wu, M. Feng, B. Han, Y. Fang, et al. (2016) Proteomic analysis reveals the molecular underpinnings of mandibular gland development and lipid metabolism in two lines of honeybees (Apis mellifera ligustica). J. Proteome Res. 15: 3342-3357.

Izuta H., M. Shimazawa, K. Tsuruma, Y. Araki, S. Mishima, et al. (2009) Bee products prevent VEGF-induced angiogenesis in human umbilical vein endothelial cells. BMC complementary and alternative medicine 9: 45 .

Ji T., Z. Liu, J. Shen, F. Shen, Q. Liang, et al. (2014) Proteomics analysis reveals protein expression differences for hypopharyngeal gland activity in the honeybee, Apis mellifera carnica Pollmann. BMC Genomics 15: 1-14.

Kocot J., M. Kielczykowska, D. Luchowska-Kocot, J. Kurzepa, I. Musik. (2018) Antioxidant potential of propolis, bee pollen, and royal jelly: Possible medical application. Oxidative medicine and cellular longevity 2018: 7074209.

Kolayli S., H. Sahin, Z. Can, O. Yildiz, M. Malkoc, et al. (2016) A member of complementary medicinal food: Anatolian royal jellies, their chemical compositions, and antioxidant properties. Journal of evidence-based complementary \& alternative medicine 21 (4): NP43-48.

Krell R. (1996) Value-added products from beekeeping. FAO Agricultural Services Bulletin, 124, Food and Agriculture Organization of the United Nations, Rome, Italy.

Kubo T., M. Sasaki, J. Nakamura, H. Sasagawa, K. Ohashi, et al. (1996) Change in the expression of hypopharyngeal-gland proteins of the worker honeybees (Apis mellifera L.) with age and/or role. J. Biochem. 119 : 291-295.

Lercker G., P. Capella, L.S. Conte, F. Ruini, G. Giordani. (1981) Components of royal jelly: I. Identification of the organic acids. Lipids 16 : 912-919.

Li J. (2000) Technology for royal jelly production. Am Bee J 140 : 469-472.

Li J., W. Aiping. (2005) Comprehensive technology for maximizing royal jelly production. Am Bee J 145 : 661-664.

Li J., S.-L. Chen, B.-X. Zhong, S. Su. (2003a) Genetic analysis for developmental behavior of honeybee colony's royal jelly production traits in western honeybees. Acta genetica Sinica 30 : 547-554.

Li J., C. Shenglu, Z. Boxiong, S. Songrun. (2003b) Optimizing royal jelly production. Good queens are a must. American Bee Journal 143 : 221-223.

Li J., L. Huawei, Z. Zhaohui, P. Yinghong. (2007a) Identification of the proteome complement of high royal jelly producing bees (Apis mellifera) during worker larval development. Apidologie 38 : 545-557.

Li J., T. Wang, Z. Zhang, Y. Pan. (2007b) Proteomic analysis of royal jelly from three strains of western honeybees (Apis mellifera). J. Agric. Food Chem. 55 : 8411-8422.

Li J., M. Feng, Z. Zhaohui, P. Yinghong. (2008) Identification of the proteome complement of hypopharyngeal glands from two strains of honeybees (Apis mellifera). Apidologie 39: 199-214.

Li J., M. Feng, D. Begna, F. Yu, Z. Aijuan. (2010) Proteome comparison of hypopharyngeal gland development between Italian and royal jelly producing worker honeybees (Apis mellifera L.). J. Proteome Res. 9: 6578-6594.

Liang-xian S., C. Chao-yang, Y. Jian-jun, X. Jin-jin. (2004) Genetic variability of MDHII in four lines of Apis mellifera ligustica. J Coll Sci Teach 17 : 54-59.

Liu J.-R., Y.-C. Yang, L.-S. Shi, C.-C. Peng. (2008) Antioxidant properties of royal jelly associated with larval age and time of harvest. J. Agric. Food Chem. 56 (23): 11447-11452.

Liu F., S. Su, Y. Wang, S. Pan, X. Zheng, et al. (2011) Advanced mechanization of royal jelly production. Bee World 7618: 44-45.

Mairesse N., D. Bernaert, G. Del Bino, S. Horman, R. Mosselmans, et al. (1998) Expression of HSP27 results in increased sensitivity to tumor necrosis factor, etoposide, and $\mathrm{H} 2 \mathrm{O} 2$ in an oxidative stress-resistant cell line. J. Cell. Physiol 177 : 606-617.

Matysiak J., J. Hajduk, L. Pietrzak, C.E.H. Schmelzer, Z.J. Kokot. (2014) Shotgun proteome analysis of honeybee venom using targeted enrichment strategies. Toxicon $90: 255-264$.

Matysiak J., J. Hajduk, F. Mayer, R. Hebeler, Z.J. Kokot. (2016) Hyphenated LC-MALDI-ToF/ToF and LC-ESIQToF approach in proteomic characterization of honeybee venom. J. Pharm. Biomed. Anal. 121 : 69-76.

Matysiak J., J. Hajduk, A. Swiatly, N. Naskret, Z.J. Kokot. (2017) Proteomic analysis of Apis mellifera venom determined by liquid chromatography (LC) coupled with nano-LC-MALDI-TOF/TOF MS. Acta Pol. Pharm. 74 (1): 53-65.

Melliou E., I. Chinou. (2005) Chemistry and bioactivity of royal jelly from Greece. J. Agric. Food Chem. 53 : 8987-8992.

Meng L., X. Huo, M. Feng, Y. Fang, B. Han, et al. (2018) Proteomics reveals the molecular underpinnings of stronger learning and memory in eastern compared to western bees. Mol. Cell. Proteomics 17 (2): 255-269.

Miyata Y., H. Sakai. (2018) Anti-cancer and protective effects of royal jelly for therapy-induced toxicities in malignancies. Int. J. Mol. Sci 19(10).

Moraes R.L.M.S.D.E., I.D. Bowen. (2000) Modes of cell death in the hypopharyngeal gland of the honey bee (Apis mellifera L). Cell Biol. Int. 24 : 737-743.

Nakajima Y., K. Tsuruma, M. Shimazawa, S. Mishima, H. Hara. (2009) Comparison of bee products based on assays of antioxidant capacities. BMC Complementary and Alternative Medicine 9(1): 4.

Nie H., X. Liu, J. Pan, W. Li, Z. Li, et al. (2017) Identification of genes related to high royal jelly production in 
the honey bee (Apis mellifera) using microarray analysis. Genet. Mol. Biol. 789 : 781-789.

Ohashi K., M. Sawata, H. Takeuchi, S. Natori, T. Kubo. (1996) Molecular cloning of cDNA and analysis of expression of the gene for alpha-glucosidase from the hypopharyngeal gland of the honeybee Apis mellifera $L$, Biochem Biophys Res Commun, pp. 380-385.

Ohashi K., S. Natori, T. Kubo. (1997) Change in the mode of gene expression of the hypopharyngeal gland cells with an age-dependent role change of the worker honeybee Apis mellifera L. Eur. J. Biochem. 249 : 797-802.

Ohashi K., S. Natori, T. Kubo. (1999) Expression of amylase and glucose oxidase in the hypopharyngeal gland with an age-dependent role change of the worker honeybee (Apis mellifera L .). Eur. J. Biochem. 133 : 127-133.

Ohashi K., Sasaki M., Sasagawa H., Nakamura J., Natori S., Kubo T. (2000) Functional Flexibility of the Honey Bee Hypopharyngeal Gland in a Dequeened Colony. Zool. Sci. 17:1089-1094.

Oka H., Y. Emori, N. Kobayashi, Y. Hayashi, K. Nomoto. (2001) Suppression of allergic reactions by royal jelly in association with the restoration of macrophage function and the improvement of Th1/Th2 cell responses. Int. Immunopharmacol. 1 : 521-532.

Okamoto I., Y. Taniguchi, T. Kunikata, K. Kohno, K. Iwaki, et al. (2003) Major royal jelly protein 3 modulates immune responses in vitro and in vivo. Life Sci. 73 : 2029-2045.

Parker R., M.M. Guarna, A.P. Melathopoulos, K.-M. Moon, R. White, et al. (2012) Correlation of proteome-wide changes with social immunity behaviors provides insight into resistance to the parasitic mite, Varroa destructor, in the honey bee (Apis mellifera). Genome Biology 13 (9).

Peixoto L.G., L.K. Calábria, L. Garcia, F.E. Capparelli, L.R. Goulart, et al. (2009) Identification of major royal jelly proteins in the brain of the honeybee Apis mellifera. J. Insect Physiol. 55 : 671-677.

Plettner E., K. N. Slessor, M. L. Winston, J. E. Oliver. (1996) Caste-selective pheromone biosynthesis in honeybees. Science 271 : 1851-1853.

Qi Y., P. Fan, Y. Hao, B. Han, Y. Fang, et al. (2015) Phosphoproteomic Analysis of Protein Phosphorylation Networks in the Hypopharyngeal Gland of Honeybee Workers (Apis mellifera ligustica). J. Proteome Res. 14 (11): 4647-4661.

Qiu J.B. (1999) Review of the production and development of Chinese royal jelly. Bee Magazine (in Chinese) 10 : 8-9.

Ramadan M.F., A. Al-Ghamdi. (2012) Bioactive compounds and health-promoting properties of royal jelly: A review. J Funct Foods 4 : 39-52.

Randolt K., O. Gimple, J. Geissendörfer, J. Reinders, C. Prusko, et al. (2008) Immune-related proteins induced in the hemolymph after aseptic and septic injury differ in honey bee worker larvae and adults. Arch. Insect Biochem. Physiol. 69 : 155-167.

Santos K.S., L. Delazari Dos Santos, M. Anita Mendes, B. Monson De Souza, O. Malaspina, et al. (2005) Profiling the proteome complement of the secretion from hypopharyngeal gland of Africanized nurse-honeybees (Apis mellifera L.). Insect Biochem. Mol. Biol. 35 : 85-91.

Sasagawa H., M. Sasaki, I. Okada. (1989) Hormonal control of the division of labor in adult honeybees (Apis mellifera L.). I. Effect of methoprene on corpora allata and hypopharyngeal gland, and its $\alpha$-glucosidase activity. Appl. Entomol. Zool. 24 : 66-77.

Schmitzová J., J. Klaudiny, Š. Albert, W. Schröder, W. Schreckengost, et al. (1998) A family of major royal jelly proteins of the honeybee Apis mellifera $L$. Cell. Mol. Life Sci. 54 : 1020-1030.

Simpson J., I.B.M. Riedel, N. Wilding. (1968) Invertase in the Hypopharyngeal Glands of the Honeybee. J. Apic. Res. 7: 29-36.

Su S., S.-L. Chen. (2003) Research on morphological genetic marker of honeybee (Apis melli fera ligustica) in royal jelly production performance. Hereditas 25 : 677-680.

Suryamohan K., M.S. Halfon. (2015) Insect regulatory genomics, in: Raman C., Goldsmith M.R., and Agunbiade T.A. (Eds.), Short Views on Insect Genomics and Proteomics: Insect Genomics, Vol.1, Springer International Publishing, Cham, pp. 119-155.

Tokunaga K.-h., C. Yoshida, K.-m. Suzuki, H. Maruyama, Y. Futamura, et al. (2004) Antihypertensive effect of peptides from royal jelly in spontaneously hypertensive rats. Biol. Pharm. Bull. 27 : 189-192.

Townsend G.F., J.F. Morgan, B. Hazlett. (1959) Activity of 10-hydroxydecenoic acid from royal jelly against experimental leukaemia and ascitic tumours. Nature 183 (4670): 1270-1271.

Valcu C.M., B. Kempenaers. (2015) Proteomics in behavioral ecology. Behav. Ecol. 26 : 1-15.

Vallet A., P. Cassier, Y. Lensky. (1991) Ontogeny of the fine structure of the mandibular glands of the honeybee (Apis mellifera $L$.) workers and the pheromonal activity of 2-heptanone. J. Insect Physiol. 37 : 789-804.

Viuda-Martos M., Y. Ruiz-Navajas, J. Fernández-López, J.A. Pérez-Álvarez. (2008) Functional properties of honey, propolis, and royal jelly. J. Food Sci. 73 : 117-124.

Vucevic D., E. Melliou, S. Vasilijic, S. Gasic, P. Ivanovski, et al. (2007) Fatty acids isolated from royal jelly modulate dendritic cell-mediated immune response in vitro. Int. Immunopharmacol. $7:$ 1211-1220.

Wencheng H., X. Daikui, S. Jikai, C. Shibi, C. Shenglu, et al. (1989) Study on the performance of royal jelly produced by a high-yielding Italian bee colony of Pinghu. China Bee Industry (in Chinese) $1: 3-5$.

Wu X.-B., F. Zhang, C. Guan, Q.-Z. Pan, L.-B. Zhou, et al. (2015) A new method of royal jelly harvesting without grafting larvae. Entomol. News 124 (4): 277-281.

Wu Y.Q., H.Q. Zheng, M. Corona, C. Pirk, F. Meng, et al. (2017) Comparative transcriptome analysis on the synthesis pathway of honey bee (Apis mellifera) mandibular gland secretions. Scientific Reports $7: 1-10$.

Yang Y.C., W.M. Chou, D.A. Widowati, I.P. Lin, C.C. Peng. (2018) 10-hydroxy-2-decenoic acid of royal 
jelly exhibits bactericide and anti-inflammatory activity in human colon cancer cells. BMC complementary and alternative medicine 18(1): 202.

Yin L., T. Ji, G. Chen, W. Peng. (2011) Genetic characterization of three breeds of high royal jelly producing honeybee (Apis mellifera ligustica) in China. J. Agric. Res. 6 : 331-337.

Yoneshiro T., R. Kaede, K. Nagaya, J. Aoyama, M. Saito, et al. (2018) Royal jelly ameliorates diet-induced obesity and glucose intolerance by promoting brown adipose tissue thermogenesis in mice. Obesity Research and Clinical Practice 12 (1): 127-137.

Yuksel S., S. Akyol. (2016) The consumption of propolis and royal jelly in preventing upper respiratory tract infections and as dietary supplementation in children. Journal of intercultural ethnopharmacology 5 (3): 308-311.

Zewdu Ararso H., A. Solomon Zewdu, W. Abebe Jemberie, J. Li. (2018) Proteomics improves the new understanding of honeybee biology. J. Agric. Food Chem. 66 (14): 3605-3615.
Zhang Y.J., Y. Jiang, W.P. Wang, C.F. Wang, F.C. Ge, et al. (2001) Study on a special marker-W316bp in $A . m$. ligustica of high royal jelly products. Apiculture of China 52: 7-9.

Zhang Y.J., Y. Jiang, W.P. Wang, C.F. Wang, F.C. Ge, et al. (2013) Research and application of key technique for mechanized production of royal jelly (I)-a design of bionic non-grafting larvae ovipositor. Acta Agric. Univ. Jiangxiensis 35 : 842-847.

Zhang L., B. Han, R. Li, X. Lu, A. Nie, et al. (2014) Comprehensive identification of novel proteins and $\mathrm{N}$-glycosylation sites in royal jelly. BMC Genomics 15: $1-14$.

Zheng H.-Q., W.-T. Wei, F.-L. Hu. (2011) Beekeeping industry in China. Bee World 88: 41-44.

Publisher's note Springer Nature remains neutral with regard to jurisdictional claims in published maps and institutional affiliations. 